\title{
A TYPOLOGY OF MORAL CONVERSION $^{1}$
}

\author{
Alfredo MacLaughlin \\ Loyola University \\ Chicago, Illinois
}

Moral conversion is a favorite and much desired theme in almost any kind of narrative. Consider the many "change of heart" stories ("change of heart" being another name for moral conversion) that populate the big and the small screen: the cynical pennycounter that becomes a warm-hearted boss and philanthropist, Dickens's Scrooge in his various incarnations; the workaholic father that after a crisis of some sort opts for a less frantic lifestyle; the fast-paced broker becoming a small-league trainer; odd couples becoming lifelong friends; the popular, fashion-focused teen disengaging from her exclusive clique and opening up to systematically excluded potential friendships, the cowardly bystander standing up to support the hero or heroine, and so forth. These and other stories are the bread-and-butter of mainstream and independent drama and comedy alike and are at least an expected subplot in stories that focus on action or suspense. Tragedies too, both classical and contemporary, are constructed around this theme also, though commonly they focus on this process becoming frustrated: Creon, refusing to listen to his son, his people, and the voice of the gods, or Macbeth cowering at the sight of blood and ghosts but continuing on his murderous, self-destructive course.

More importantly, moral conversion is an important element of

1 This paper is a much shortened version of the fifth chapter in my dissertation Narratives of Hope: A Philosophical Study of Moral Conversion (Loyola University, Chicago, 2008). The wording is in many cases identical, although the corresponding chapter investigates the topic in greater detail and explores many more cases. This paper was discussed during the afternoon workshop on Moral Conversion, at the $36^{\text {th }}$ Annual Lonergan Workshop (Boston College, June 2009). 
real moral experience, whether as a process that actually takes place, or in the form of hope for change in oneself or others. The hope for moral conversion is sufficiently common in everyday experience to require little proof of its presence: it is the reason, for good or ill, why people continue to put their trust on those who have disappointed them already, perhaps more than once. Whether moral conversion actually takes place requires, however, some form of demonstration; and this is one of the goals that this papers attempts to achieve.

Since moral conversion is such a frequent element in narratives, and arguably also an important element in moral experience, it is somewhat surprising that it has received so little attention from philosophers, as well as from other disciplines that study moral life. ${ }^{2}$ This may be partially explained by the fact that moral conversion is constitutively a surprising event, surprising in many senses. It is surprising, first, in the sense that it often takes place without anyone expecting it, not even the subject of conversion him/herself. It is also surprising in the sense that, even when expected or desired, its outcome is uncertain, and its taking place brings a joyful amount of surprise for those that desire it. It defies, in other words, prediction, whether this be the kind of prediction originated in the methodological observation of patterns of probability, or the everyday prediction of experienced people who have seen it happen many times - and thus moral conversion is not normally discussed, for example, in empirically based analyses of moral development. This quality makes it somewhat of an unwieldy topic.

The difficulty in satisfactorily circumscribing the notion of moral

2 The notion of "moral conversion" appeared very rarely in the literature, until it was discussed in the past century by Bernard Lonergan, in the context of the triad intellectual, moral, and religious conversion. This produced as a result a renewed philosophical and theological interest in conversion, and the resulting scholarship produced most of the literature available now that deals specifically with moral conversion. Even so, such literature is very scarce, since Lonergan scholars have focused mostly on the analysis of intellectual and religious conversion, and only sporadically dedicated more than passing reflections to it. Walter Conn, to whom I am thankful, is probably the scholar that has devoted most time to its study, devoting to it a couple of chapters in Christian Conversion: A Developmental Interpretation of Autonomy and Surrender (New York: Paulist Press, 1986); but the notion of moral conversion he works on is developed from a very specifically Lonerganian context, and as such it is not broad enough to include various classes of moral conversion that need to be considered for a more substantial treatment. 
conversion adds to this unwieldiness. The principal objective of this paper is to establish a typology of moral conversion, one that will serve additionally to define what is meant by "moral conversion" in a way that is both specific enough to make it susceptible of philosophical analysis, and inclusive enough to honor the notorious diversity of ways in which human life can be affected by moral conversion. ${ }^{3}$

\section{The Notion of "Conversion"}

Conversion has most frequently been studied within the realms of theology and religious studies (or, within the realm of psychology, as a subtopic within the larger topic of psychology of religious phenomena), and as a consequence conversion is frequently understood to mean religious conversion. The meaning of the term, however, is far broader. Intellectual, moral, affective, psychological, aesthetic, social types of conversion have been identified by those having these experiences, and by scholars who have studied them. Possibly the list could be expanded to include further types. ${ }^{4}$

On a first look, the common element among these notions seems to be some form of change in the person. This change is of tremendous importance to the person, in the sense that the relations of the person to the world, to others, to truth, even to the self are fundamentally affected. How the person is affected, and in respect to which aspect of the person's relation to the world, to others, to truth or to self is what identifies the type of conversion involved.

3 This categorization, it is hoped, will help jump-start a discussion that has been lately mostly abandoned. A reason for this abandonment, I believe, is precisely the absence of a proper categorization/definition of moral conversion. Many profound definitions have been put forward; Lonergan's "a move from the criterion of satisfaction to the criterion of value" is a good example (Bernard Lonergan, Method in Theology, 2nd. ed. [New York: Herder and Herder, 1973; reprint, 1994 by University of Toronto Press], 240). But these definitions often operate within complex universes of meaning that need to be grasped before the definition entirely makes sense, and that are not sufficiently inclusive. The present typology operates at a more basic level, categorizing moral conversion in terms that do not require the previous understanding of (nor agreement to) a specific, sophisticate analysis of moral life.

4 The key texts for conversion in Lonergan are in Method in Theology, 237-43. A very detailed analysis of the evolution of the notion of conversion in Lonergan can be found in Michael L. Rende, Lonergan on Conversion: The Development of a Notion (Lanham, MD: University Press of America, 1991). 
I propose to use the term "existential" as a key way of characterizing the kind of change that conversion constitutes. ${ }^{5}$ The term "existential" is itself difficult to pin down precisely, given how it is used in widely different contexts - and sometimes rather loosely - in contemporary philosophy; but it captures very adequately in its general meaning some essential characters of conversion. It draws attention to the importance of the change (as in expressions such as "she made an existential decision"). It draws attention to something being real and concrete, as opposed to something being "merely academic," detachedly theoretical, and so forth. It has, in third place, the connotation of something being personal - in contrast, for example, to structural changes happening to institutions, to the restructuring of systems of law, to the training of animals, not to mention material changes in physical structures. In fourth place, it can be used to emphasize the contingency of the concrete: the fact that things happen that are not planned, plans fail, accidents occur, and contingency in general cannot be excluded from human existence by any amount of rational planning. This connotation of the term "existential" also applies to conversion, insofar as conversions typically have an element of unexpectedness, even of working against expectations. Lastly, the term "existential" brings forth that emphasis, so dear to the philosophical tradition named precisely "existentialism," on freedom, and specifically on freedom as a harsh blessing. The existentialists' discussions of freedom provide a suitable platform for examining the issue of whether conversion is an event that requires the freedom of the human agent to take place at all.

It can be seen thus why it would be useful to define conversion as an existential change. It is not the intention of this paper, however, to defend this characterization; it is proposed here only as an introductory approach to the meaning of the notion. A proper discussion of the adequacy of this characterization would have to follow a more basic

5 The idea for this use of the term "existential" is based on a discussion between Walter Conn and John Gibbs regarding whether Kohlberg's postconventional stages of moral reasoning are reached through a "natural/spontaneous" dynamism or an "existential" one, the latter requiring explicit conscious awareness on the part of the agent. See Conn, Christian Conversion, 107-34; John C. Gibbs, "Kohlberg's Stages of Moral Development: A Constructive Critique," Harvard Educational Review 47, no. 1 (1977); Alfredo MacLaughlin, Narratives of Hope: A Philosophical Study of Moral Conversion (Ph.D. Diss., Loyola University Chicago, 2008; available from http://www.proquest.com, publication number AAT 3332357), 205-27. 
circumscription of the term, which is what is attempted below. ${ }^{6}$

\section{Toward a Notion of Moral Conversion}

The typology presented in this paper is structured on the basis of two distinctions, that are then cross-related. These are briefly presented here in order to make the subsequent exposition clearer. The first distinction concerns the different focus given to the question about the meaning of morality by classical and by modern/contemporary philosophy. While the modern/contemporary investigations on ethical theory have focused strongly on the question on right and wrong, there is a classical understanding of the subject-matter of ethical theory (common to both Plato, Aristotle, and Christian medieval philosophers) that focuses rather on the question for happiness and "the good life" (contemporarily phrased also as "the meaning of life" question). In principle, both provide acceptable - if incomplete - ways of answering the question about what constitutes a matter of moral concern, and consequently, what differentiates moral conversion from other types of conversion. Collapsing both meanings, however, can only be attempted at the cost of much confusion, or by a highly elaborate moral theory that may or may not succeed in bringing both together in satisfactory ways. I will therefore address these two meanings of morality separately.

The second distinction concerns the meaning of conversion itself. A closer look at the phenomenon shows that its manifestations can be enormously varied, rendering a definition aimed at covering all or nearly all instances of conversion extremely general and vague. Thus, rather than attempting to articulate one common but overly general and vague definition of moral conversion, the task of circumscribing the notion for present purposes will be accomplished by differentiating three general "classes" of conversion: conversion regarding content, conversion regarding attitude or degree of commitment, and conversion regarding behavioral coherence.

\section{The Use of Narrative Evidence}

Each of these processes entails a change profound enough and

\footnotetext{
6 For a fuller treatment of the characterization of conversion as "existential," see MacLaughlin, Narratives of Hope, 193.
} 
existential enough to merit the name of conversion as was indicated. For each category in the typology, the fact that moral conversion takes place in such a way needs to be established. There is no shortage of views, both in the spheres of common sense and philosophical reflection, that reject the possibility of human beings changing morally for the better - whether on the grounds of a pessimistic view of human nature that considers human beings just too strongly drawn toward selfish behavior, dishonesty, inauthenticity, the abuse of power, and other forms of behavior generally regarded as morally lacking; or whether on the grounds of deterministic views that consider the change itself to be impossible, either from the belief that moral behavior is, for good or ill, entirely determined by original, inherited tendencies, or from the belief that change becomes impossible once a person's moral views and moral habits settle in, "crystallize," so to speak. These views cannot be addressed directly within the scope of this paper, ${ }^{7}$ but their presence determines that the fact of moral conversion cannot be simply granted. That moral conversion actually takes place has to be proved, and this in turn demands a specific methodology. The problem will be addressed by providing, at the point in which each category is discussed, what is called here "narrative evidence": evidence from real-life stories that exemplify and demonstrate the possibility of moral conversion in very diverse areas of life (political commitment, criminal rehabilitation, career shifts, alcoholic recovery, etc). To keep this paper to a reasonable size, I will only include an example or two in the discussion of each category; a more substantial collection of narratives is included in my dissertation. ${ }^{8}$

\footnotetext{
7 They are discussed in detail in MacLaughlin, Narratives of Hope, 261-327.

8 MacLaughlin, Narratives of Hope, 261-37. Because conversion is understood here not merely as a change in externally observable, behavioral patterns, but (as the typology will make it clear) more fundamentally as a change in a person's ways of thinking, judging, and valuing in moral matters and also because an understanding of the intellectual, emotional, and volitional processes involved is sought, it is necessary that the narrative evidence provided goes beyond an external description of behavioral changes, or a statement of the observable evidence of a person's moral convictions "before and after" the change takes place, and gain as much insight as possible into such processes. This requirement imposes the methodological need to focus on a small number of narratives that provide sufficiently rich descriptions, rather than to attempt a more extensive but "shallower" survey that could provide statistically significant data but that would serve little purpose for this project. In other words, the methodology employed
} 


\section{THE MODERN/CONTEMPORARY NOTION OF MORALITY: MORAL CONVERSION REGARDING RIGHT AND WRONG}

The modern/contemporary approach to the meaning of "moral" is not itself devoid of ambiguity. Two approaches are commonly encountered when investigating this meaning. One common approach is to begin the discussion by asking about the meaning of "right" and "wrong," the polarity most frequently associated with moral judgments. Another very common approach begins with a discussion on the experience of "oughtness," the peculiarly human experience of regarding oneself as duty-bound with respect to certain courses of action; the problem, in other words, of moral obligation. ${ }^{9}$ The two approaches, "right/wrong" and "obligation," are intrinsically bound to each other; they may or may not eventually be collapsed into one, leading to significant differences in moral theory. To simplify matters, I will consider them in a single category during the course of this article, and will refer to them with the expression "right/wrong."

This common focus in contemporary discussion provides us with a first meaning for "moral conversion": a change in the subject (or moral agent) with regard to her/his existential involvement in the task of acting rightly or wrongly, of doing what ought to be done. This change may involve both big, consequential decisions and the small, perhaps half-thought actions of daily life. In relation to this focus, it is possible to identify three distinct processes that can be called "moral conversion."

\section{A. Moral Conversion Regarding the Content of Right and Wrong}

The first class of conversion focuses on significant changes in what is considered to be right/wrong in general.

It should not be difficult for the reader to recall instances of changing one's moral judgment on some specific issue or other: a practice about which one previously had no moral objections comes

(and the epistemological challenges it may encounter) is closer to that of the historian than to that of the sociologist. The preferential use of narratives of a biographical and autobiographical kind responds to this specific need.

9 The more classically minded reader will perhaps initiate the discussion by asking about what constitutes "the good life." This approach will be taken into consideration later in this article. 
to be considered objectionable, for example, in the light of such new information as its negative environmental impact or its exploitative background; or because a new argument or point of view is presented that one had not previously considered. Such changes in judgment or opinion - hopefully a normal occurrence in the moral life of an intellectually active person - are not what is referred to here as instances of moral conversion.

But one can also imagine (and perhaps recall) a change in a person's moral judgment about the said practice happening due to a more fundamental shift in that person's basic criteria for judging: in the wake of this shift, a revision of moral conclusions and previously accepted rules takes place. A person, for example, begins to include the potential environmental consequences of his/her acts as an important criterion for decision, when previously there was no consideration of the importance of this factor. This kind of change - even if the example chosen is relatively innocent or uncontroversial - affects the structure of a person's moral judgment. Furthermore, it normally affects quite extensively a person's life. A number of everyday practices and habits need to be changed; life requires restructuring. This restructuring may affect also that person's relations, who may react positively or negatively to such changes, offering encourage or resistance, and overall expressing that the person has changed his/her value in their eyes. This is the kind of change that merits the name of "moral conversion."

Alternatively, the change described may affect not just a criterion or set of criteria, but the entire process by which a person arrives at a moral judgment: the person, for example, might shift from being strictly rule-abiding to an outcome-focused form of compliance, and thus weigh his/her actions accordingly, by examining in each case the potential consequences of acting one way or another. ${ }^{10}$

Such is the first class of moral conversion: a change in the person's criteria for moral judgment - or in the process of moral judging itself so important as to expand into a significant life change.

10 Sometimes such a change in the criteria for moral reasoning is accompanied by a shift of another sort: the move from a life ruled by uncritically accepted moral principles and/or rules, to a life in which one's criteria for moral action are habitually reflected upon, weighed, and critically considered. This is what Conn calls a "critical moral conversion": a moral conversion that is coupled with some degree of intellectual conversion. 


\section{Narrative Evidence for this Class of Conversion ${ }^{11}$}

An instance of moral conversion regarding content about right/ wrong is found in Donald Gelpi's account of his own conversion from racism. Having been born in New Orleans, Louisiana, Gelpi avows to having grown up "a racial bigot," his racism focusing on black people.

I do not remember ever doing anything to hurt black people, but I did grow up believing in their essential racial inferiority to myself and to other white people.

No one challenged my racial bigotry in a systematic way until I went to high school. The Jesuits who taught me waged ceaseless war on my racism and on the racism of my white classmates. I resisted them for two years, but eventually I conceded that they had the right of it. I recognized the immorality of racism and renounced it in my own heart. ${ }^{12}$

Gelpi's account is devoid of dramatic overtones: he acknowledges in simple terms the fact that he essentially agreed with racist views despite not having consciously hurt anyone on account of such views - and that in a two-year process eventually came to see such views as immoral and renounce them. There is clearly a significant change in the content of what he regarded as right/wrong, despite his having grown up immersed in such views, and despite the fact that his resistance to change was being supported by his classmates. Gelpi also identifies in this instance of conversion a deeper kind of change:

I look back on that experience as a personal moral conversion.

I regard it as an initial moral conversion because, for the first time in my life, I took personal responsibility for my disagreeing with the conventional morality taught me by my society. By disagreeing, I took personal responsibility for my

11 As anticipated, in order to go beyond a mere description of categories and show that these categories describe something that actually takes place, each section of this paper describing a class of conversion will be accompanied by a subsection providing narrative evidence. The evidence provided is drawn from a survey of biographies, interviews, psychological and sociological investigations, and similar sources.

12 Donald Gelpi, The Conversion Experience: A Reflective Process for R.C.I.A. Participants and Others (New York: Paulist Press, 1998), 29. 
own conscience. ${ }^{13}$

This transition - in Gelpi's words, a transition from "conventional to autonomous morality"14 - is an instance and an example of a shift in criteria for moral judgment that is accompanied and supported by a cognitive conversion: Gelpi experiences a shift toward a need for reasoned support for his moral views and practices, as opposed to accepting as sufficient evidence for them the fact of their widespread acceptance.

Robert Bellah provides another example in his interview of Wayne Bauer. ${ }^{15}$ Raised in an unreflective acceptance of traditional patriotic values, Wayne joined the Marine Corps in the sixties; but during this time, friends who had gone to college began to argue with him about the Vietnam War. These discussions went on for a few months, and Bauer finally concluded that his best arguments "held no weight." 16 His resolution was strong enough, in practical terms, to lead him to go AWOL, thus being forced to lead an underground life for many years. Eventually he surrendered to the military, was spared a court martial, and became a political activist and an advocate for poor tenants (an instance of a conversion regarding content about happiness and the meaning of life); but this long process began in a moral conversion regarding content about right/wrong: he came to see joining the military and engaging on the military activities of the time as morally objectionable and acted accordingly.

These examples should suffice to indicate the reality of this class of conversion.

\section{B. Moral Conversion Regarding the Degree of Commitment with Respect to Right/Wrong}

Another class of moral conversion can be described as a shift from a general lack of concern for the morality of one's actions to genuine concern for this. An initial way to characterize this class of moral

13 Gelpi, The Conversion Experience, 29.

14 Gelpi, The Conversion Experience, 30.

15 Robert N. Bellah and others, Habits of the Heart: Individualism and Commitment in American Life (Berkeley: University of California Press, 1985), 17-20.

16 Bellah and others, Habits of the Heart, 17-20. 
conversion could be as a conversion "from frivolity to seriousness," or "from amorality to morality." The rules and principles that previously defined right and wrong for a person, and that were in all probability learnt in that person's childhood, may have been up to that point regarded as nonbinding; perhaps as rules that, while laid down by society in general, are to be followed only by those obedient enough to abide by them. But when this class of moral conversion takes place, these rules and principles, previously comprehended in this detached manner, become now existentially pressing for the person. No longer are these rules something exclusively "for other people." Nor are they regarded as rules that one "happens to follow" arbitrarily but are now followed because they are grasped as binding on all moral persons, or essential to the maintenance of one's moral identity.

On closer analysis, however, the characterization of this class of conversion becomes more complex. To begin with, quite a bit of variety can be found in the shapes that this class of conversion can take, and some ambiguity, even controversy, in their valuation. Simone de Beauvoir for example, in The Ethics of Ambiguity, ${ }^{17}$ has traced a number of moral/existential profiles that range from the "Serious Man," - a dangerous being, in her account, who takes the world to be the source of absolute, unconditioned values - to the "Free Man" who, aware of the (claimed) absence of such unconditioned values, commits to the existentialist ideal of the exercise of his freedom; and in so doing, by accepting the freedom of others as something like an absolute, regains a "legitimate" kind of seriousness. In her description we find a number of moral profiles - the "sub-men," the Adventurer, the Nihilist, the Passionate Man - characterized in subtle distinctions by the ways in which they commit to values, including whether they regard them as absolute and unconditional or as something else. ${ }^{18}$

Secondly, the inverse process is also conceivable. A person who lived by certain rules believing that they should be followed may come to doubt their foundations, or their hold on him/her in terms of right/ wrong, and so become more distanced and no longer see him/herself

17 Simone de Beauvoir, The Ethics of Ambiguity (New York: Philosophical Library, 1949).

18 De Beauvoir, The Ethics of Ambiguity, 51. Interestingly, de Beauvoir uses the actual term "conversion" to describe the movement to a profile closer to the "Free Man" ideal. 
under their rule. Should this process be considered just another form of conversion, or perhaps a "counter-conversion," with the same characteristics but an inverse moral sign? None of these alternatives seems to be adequate: such a process is rarely the exact inverse, for while the shift toward a higher degree of commitment usually entails a process of "positive" determination on the side of the agent, its opposite usually resembles rather a process of decreasing determination, disintegration, an "entropic" process, so to speak. Such a process fits neither the use of the term "conversion" in its common, everyday usage - so it is rarely called a conversion - nor the technical use of the term as developed in this work. The matter cannot be discussed in further detail here, since this would require a fleshed-out ethical theory addressing the issues of moral progress and decadence. Only the suggestion is made here that the matter may be usefully approached by examining whether the process can be categorized in terms of integration or disintegration.

\section{Narrative Evidence for this Class of Conversion}

Often a change in attitude will be accompanied by a change in the way the person perceives moral issues (i.e., content). Thus a conversion will be considered to fit the present class not when there is no change regarding content, but when, even if significant changes regarding content can be identified, the attitudinal change appears to be more significant. The well-known story of Mohandas Gandhi being forced out of the train may be read in this light. ${ }^{19}$ While traveling first class through Natal, South Africa, as representative of his Indian law firm, an official told him (because of his "coloured" skin) that he should move to third-class. When he refused, the official called a constable that then took him by the hand and forced him out of the train, together with his luggage. Gandhi then sat in the waiting room, dark and cold, and considered whether to fight for his rights, to continue on his journey without responding to the insults, or - ultimately his choice - to dedicate himself "to root out the disease and suffer hardships in the process. ${ }^{20}$

19 M. K. Gandhi, An Autobiography; or the Story of My Experiments with Truth, trans. Mahadev Desai (Ahmedabad, India: Navajivan Publishing House, 1927), 103-105.

20 Gandhi, An Autobiography, 104. 
The change that Gandhi describes in his autobiography can be best described as a change in attitude. The injustice and the brutality of racism in general could hardly be something unknown to Gandhi at the time - he had already been involved, for example, in a similar quarrel regarding the use of turbans in court. ${ }^{21}$ But, even though the hardship he was subjected to in this episode was somewhat superficial, still the humiliation and shock seem to have acted as a sort of "triggering event," making him reevaluate the morality of ignoring the problem in general, and make a commitment; that is, adopt a new attitude, a "committed" attitude toward its solution. Gandhi does not report a significant revision of his view of the morality of racism itself on his part (i.e., a revision of the content of his moral evaluations). Rather, there is a significant change in the moral weight of the obligation to combat structural racism: it is now perceived as an imperative (a personal imperative, in Gandhi's case) that one cannot just shrug off or set aside for another time.

It is possible to find instances of a more general change in attitude toward morality in stories of people with a criminal career that significantly "reform." A narrative of this kind can be found in the story of CeaseFire activists Antonio Pickett ("Lil' Tony") and Evans Robinson ("Chip"). ${ }^{22}$ Childhood friends, both were raised in strict homes "where grace was said at the dinner table and swearing was forbidden." 23 They, however, "quickly grew enamored of the thrill and payoff of petty crime," joining a gang, eventually getting into drug dealing, and beginning their rotation in and out of prison. By 1996, though, Tony found himself facing conviction, and weary of "worrying [that] the next person he saw might try to kill him." While awaiting placement in a state prison he let his gang's leadership know he was stepping down. He mentions the prayer and support of his mother, a "loving but stern evangelical minister," as instrumental in his "turning his life around." While he spent time in prison, his friend Chip ran wild, slowed down only by the tragedy of his cousin dying in a shooting.

When Tony was released, his mother connected him then with

\footnotetext{
21 Gandhi, An Autobiography, 100.

22 Rex W. Huppke, "Four Who Watch over the City," Chicago Tribune, December 10, 2004.

23 Huppke, "Four Who Watch over the City."
} 
CeaseFire, an initiative to take on high-risk individuals, help them find jobs and educational opportunities, and counsel them about the pitfalls of street life, and before long Tony became a counselor for CeaseFire. Chip became one of his first clients, taking with his help a factory job; and in 2002 he was also hired by CeaseFire. An article in the Chicago Tribune describes them as having significant street clout due to their criminal past, which makes them very effective in recruiting teenagers out of gangs. They are also described as loving their adrenaline-charged jobs, but also carrying the regret from having hurt people in the past and having influenced others to live a life of crime. ${ }^{24}$

From the information that can be gathered from this newspaper account, it would seem that Pickett and Robinson were not ignorant of the basic norms required in honest living - they would have learned them in their early years. Rather, they consciously disregarded them. Their conversion involves thus a new or renewed interest in leading an honest life. But while their understanding of what constitutes a honest life has not changed, in this case there seems to have been a change in their way of understanding the good of living a honest life - as, perhaps, free from the hazards and the weariness of a life of crime - and this change in their understanding may have been instrumental in their attitudinal change. Summing up his experience, for example, Robinson says: "The air smells different. The sun seems brighter. Things aren't so bleak all the time. ${ }^{25}$ His new attitude and his new understanding of life seem to go together.

Cases like this, though not run-of-the-mill, are not isolated cases. ${ }^{26}$ The opposite process is described by Patrick K., a fast-track operator who gradually got involved in a scheme with corrupt elements of his state's government. Eventually the scheme was discovered; Patrick

24 The article also quotes a police officer, Sheila McFarland of the Harrison District, attesting that "the once-notorious Chip and Tony have shown they've changed their ways. 'They've done some things in the past that we wouldn't be proud of, but in the same sense they've turned over a new leaf,' she said. 'I believe their experience out on the streets and interacting with gangs at one time has given them the ability to go out and communicate with current gang members. They're taking these people under their wings"' (Huppke, "Four Who Watch over the City"). This testimony provides further evidence to assess the stability of their conversion.

25 Huppke, "Four Who Watch over the City."

26 I provide a few more in the relevant sections of my dissertation. See Mac Laughlin, Narratives of Hope, 92. 
managed to escape with his family and became an international fugitive; but eventually the stress of this fugitive life became too much and he turned himself in. ${ }^{27}$ He tells now the story as part of his community service duty. In his account, rationalization was a very important factor in his downfall - he spent a great deal of time devising ways to convince his wife and parents that what he was doing was ethical - and so was a feeling of invulnerability or arrogance fostered by his success. Interestingly enough, his body seemed to be more aware than his conscious mind of the trouble he was getting into: it responded with constant ulcers and hair loss. The dissolution is gradual and does not seem marked by a turning toward anything. Rather, the story illustrates what Lonergan called "the flight from insight," a halfconscious attempt to avoid looking at the issue or understanding it adequately. For these reasons, it seems appropriate to withhold the term "conversion" from this type of change. ${ }^{28}$

\section{Conversion Regarding Behavioral Coherence in Right/Wrong}

It is fairly common - perhaps, indeed, a universal element in human moral experience - that even people who take morality seriously, or have an ingrained concern for doing what is moral, do not always act accordingly. "I cannot even understand my own actions," says St. Paul, "for I do not do what I want, but I do what I hate." 29 These occurrences, viewed by the actor as contrary to their best intentions of right behavior can sometimes be explained, when they occur occasionally, as accidents - due to fatigue, to strong emotions provoked by an external situation (fear, anger, anxiety), to distraction, to being in a hurry, and so forth. That is, even though one may know what is the right action,

\footnotetext{
27 Patrick K., in a talk given on March 2005 at Loyola University, Chicago.

28 This type of "downfall" - the result of discrete, sometimes half-conscious decisions rather than a conscious, determined "turning" is a favorite topic of fictional narratives too, from crime epics such as Mario Puzzo's The Godfather to fantastical allegories such as Wilde's The Picture of Dorian Gray or Charles Williams's Descent into Hell, to the social criticism of Steinbeck's The Winter of Our Discontent. It is also the stuff classic tragedies are made of, from Creon in Antigone to Macbeth - a progressive loss of control, originated in dubious or bad decisions, that eventually ends in corrupting the character's originally good (even outstanding) moral character.
}

29 Romans 7, 15. 
this may still require an energy or concentration not readily available, or perhaps a certain amount of sacrifice that seems, in the situation, more than the agent can muster. Overall, these faults can be and are commonly attributed to "human weakness," by which is meant that we human beings do not operate perfectly according to the ideal, and that in the concrete existential situation we sometimes operate even further from the ideal than what we consider an acceptable standard.

Faults of this kind are commonly distinguished, however, from those that have become a habit, patterns of behavior through which we recurrently diverge from the standard: bad habits, vices, specific weaknesses, what is sometimes called the "dominant defect" by those presenting the Ignatian Spiritual Exercises, et cetera. Such habitual flaws can coexist with an earnest commitment to moral ideals. There is no direct logical correlation between a person's commitment to moral ideals and that person's capacity for self-control: one who experiences a strong desire to be more moral may indeed be very poor at self-control. A change toward greater coherence between moral standards and actual behavior has to be, for this reason, distinguished from a change in one's degree of commitment to moral standards (i.e., the second class of moral conversion). The possibility for this class of conversion is of particular importance for the person that has maintained a high level of commitment for a long while but has not achieved the desired degree of behavioral coherence. For this person, habitual flaws may weigh heavily. She may come to live in a perpetual situation of partial resignation or despair, convinced that these flaws are unconquerable, or, alternatively, may have become nearly blind to them, ignoring them, or living with a certain amount of Sartrean "bad faith." Yet it still may happen that at a certain point in life the person encounters a source of hope, and so engages with the conviction that it is possible to change. Or the person that became used to living with his/her habitual flaws, or is nearly blind to them, is suddenly vividly awakened to them. On the wings of renewed strength and/or awareness, the person may rise to meet the challenge and conquer these flaws, finally beginning to move at a steady, determined pace - sometimes at a very fast pace - toward the much desired, better habits.

What is achieved at the end of this transition is a more complete coherence between one's moral standards and one's patterns of behavior. 
The key moment seems to be the original moment in which the person's resolve is made (not just when it is formulated, but when it somehow "clicks" and transforms the whole disposition of the person toward his/ her habitual flaws). Such is the third class of moral conversion.

\section{Narrative Evidence for this Class of Conversion}

Examples of this instance of conversion abound in literature regarding alcoholism recovery: cases of alcoholics that have given up hope of ever getting rid of their addiction, that (sometimes quite unexpectedly) find a source of strength, hope or motivation, religious or otherwise, and put themselves in a successful path of recovery. Commonly the subjects do not consider their addiction a good thing, but to varying degrees a destructive one. Many suffer greatly from knowing this; they even feel they have excluded themselves from humanity. But because of the nature of addictions, often the desire to overcome their addiction has been stalled by the subject's sense of inability to do so, the desire turning into something abstract and inoperative, so that its frustration adds an additional element of suffering. It is thus justifiable to classify a determined (and eventually successful) push to reach a higher behavioral coherence as a moral conversion regarding coherence.

The story of "Subject G," for example, from James Leuba's classical study of conversion, ${ }^{30}$ tells about a man who became an alcoholic at the age of twenty-one, losing his business and two jobs because of this. The subject reports having signed "enough abstinence pledges to cover the wall of the room," which indicates a relatively active desire/attitude toward recovery over the preceding years. But then, finding himself without money, without friends, and without a home, and practically wishing to die, a lady showed him sympathy and invited him to a mission. Her kindness made him look within. For years no one had ever cared about him; this unwonted kindly interest went to his heart. ${ }^{31}$

Going to this meeting, he was invited to "give himself to the Lord Jesus Christ with the assurance that He would save him." He accepted the offer of a bed and tried to read the material given to him; he was too

30 James H. Leuba, "A Study in the Psychology of Religious Phenomena," The American Journal of Psychology 7, no. 3 (1896): 376-77.

31 Leuba, "A Study in the Psychology of Religious Phenomena," 376-77. 
disturbed, but finally experienced peace after asking God to take him as he was. Three months after this conversion, at age forty, the subject was not only still "sober," but he opened and began managing a mission himself. ${ }^{32}$

\section{MORAL CONVERSION ACCORDING TO THE CLASSICAL NOTION OF MORALITY: THE QUESTION FOR HAPPINESS, EUDAEMONIA, OR "THE MEANING OF LIFE"}

The three classes mentioned above would be sufficient to circumscribe the notion of moral conversion, if choosing or doing what is right/ avoiding what is wrong were the only relevant elements of moral experience. The focus on right/wrong, however, leaves out many aspects of moral life that can be considered essential to it. These are aspects that were regularly taken into account in what may be called, following Servais Pinckaers's use, the "classical" notion of morality. Pinckaers denounces a shift in modern ethical theory toward obligation as the central category of ethics (what has been characterized here as the focus on right/wrong). ${ }^{33} \mathrm{He}$ contrasts this focus with the focus on happiness, which is, according to him, the keystone of ancient and medieval moral thought (as well as of the moral message of the Scriptures): this shift forces many of the classical themes of moral reflection to fit into the obligation framework, in a somewhat Procrustean way, and those that do not quite fit are left out, the result being a pauperization of the themes of moral reflection.

Of particular importance for present purposes is not to overlook the concern for happiness or eudaemonia that characterizes classical ethical theory; and, in a more contemporary formulation, the concern for the meaning of life. This concern is not only alive and present in ordinary people's moral lives but also constitutes a recurrent theme

32 Leuba, "A Study in the Psychology of Religious Phenomena," 376-77.

33 Servais Pinckaers, The Sources of Christian Ethics, trans. Sr. Mary Thomas Noble from the 3rd ed. (Washington, DC: Catholic University of America Press, 1995). Pinckaers does not specify what he means by "modern"; but it may be inferred that he refers to a tendency that had its roots in some Renaissance thinkers and culminated in the Enlightenment, its paradigmatic expression being Kant's moral treatises. This focus on obligation was carried on, mostly unchallenged, into twentieth-century ethical theories; for this reason it may better be called "modern/contemporary." 
in many stories of moral conversion. Integrating these themes in the present typology will lead us to an alternative, expanded set of scenarios that are also instances of moral conversion. ${ }^{34}$

\section{A. Conversion Regarding Content about Happiness/ Eudaemonia/Meaning}

Take as a starting point a common form of the question about eudaemonia, "what would make me truly happy?" Insofar as the question is taken with a certain degree of seriousness, a change in the habitually given answer (or even the suspicion that the answer given habitually may be wrong) can precipitate existential life-changes, that is, moral conversion. Conversion would take place when a person shifts from looking for happiness/eudaemonia/meaning in one "category of goals" to looking for it in a very different category (e.g., moving from career-related achievements to fulfillment in the service of those in need). To be considered moral conversion, however, that which is changed for something else must have been something that habitually constituted a "central focus" in the life of that person, or in other words, it must be in that specific good or category of goals in which the hopes for happiness are placed..$^{35}$ When this "central focus" shifts one can expect changes deep and overhauling, possibly entailing a substantial rescheduling of the person's resources, time commitments, and so forth, and more importantly, a restructuring of that person's priorities and values. Career changes usually involve this class of conversion, when a rethinking of one's life's goals is involved. Religious conversion often also involves this class of conversion, both in terms of the life-meaning that a religion can give, and in the more specific terms of the vocational calling that often accompanies a strong religious experience. A person's

34 In calling this notion of morality "classical," I subscribe to Pinckaers's denomination out of convenience; for it may be argued that the expanded notion of "what is a matter of moral concern" is not specific of "classical" (i.e., Western, ancient, and medieval) philosophy; but Pinckaers's denomination greatly simplifies the exposition.

35 This idea appears in William James's analysis of religious conversion: "To say that a man is 'converted' means, in these terms, that religious ideas, previously peripheral in his consciousness, now take a central place, and that religious aims form the habitual centre of his energy." William James, The Varieties of Religious Experience; a Study in Human Nature: Being the Gifford Lectures on Natural Religion Delivered at Edinburgh in 1901-1902 (New York: Mentor Books, 1958), 162. 
turning from a life of addiction or crime may also involve it, perhaps because the newly acquired sense of freedom demands of the person an expansive development in the new direction. ${ }^{36}$

\section{Narrative Evidence for This Class of Conversion}

Some of the narratives considered previously have sufficient elements of this type of conversion to be revisited here. Gandhi's story, for example: his decision not to shrug off the abuses of institutional racism but to actively combat it would lead him into an extraordinary kind of life, very different from the regular life of a barrister that he had previously envisioned. Gandhi changed his priorities and life goals quite sharply as the result of what he saw as a personal moral imperative. In a similar fashion, some of the converted alcoholics described by Leuba found a meaning-giving function as a result of their conversion regarding right/wrong: "Subject G," founded and managed a mission; John B. Gough became a "temperance orator." Similarly, "Chip" and "Lil' Tony" became CeaseFire workers. This pattern is quite significant; it suggests, among other things, a strong link between moral conversion regarding right/wrong, and an openness to finding meaning for life in responding to one's community's needs and ailments.

In a study of individualism in the United States, Robert Bellah has documented a few instances of this class of conversion in quite some detail. The case of Brian Palmer illustrates a shift from a "utilitarian individualism" to an "expressive individualism." In the interview, Palmer recalls "a considerable devotion to making money" at the root of his "utilitarian individualism."

\footnotetext{
36 There is also the possibility of a change, not in the answer given to the question, but of a change in the question itself. Whatever answer is given for example to the question, "what would make me truly happy?" might never completely dispel the originally individualistic focus of the question, and thus one might consider the possibility that the question is wrongly formulated; that an excessive focus on what makes " $m e$ " happy (what Bellah calls, in Habits of the Heart, the "therapeutic attitude") will only yield dissatisfaction or disappointment, and that therefore the only way to find an answer to the question about eudaemonia is by abandoning that formulation of the question, and asking something else. Or alternatively the question about happiness may be entirely pushed out of the way by the existential situation: a matter of duty may take priority over questions of personal happiness. When such is the case, the expression "meaning of life" may be better suited to describe this class of conversion.

37 Leuba, "A Study in the Psychology of Religious Phenomena," 343-44.
} 
Whether or not Brian felt his life was satisfying, he was deeply committed to succeeding at his career and family responsibilities. He held two full-time jobs to support his family, accepting apparently without complaint the loss of a youth in which, he himself reports, "the vast majority of my time...was devoted to giving myself pleasure of one sort of another." ${ }^{38}$

Palmer put extremely long hours at work, not questioning his commitment, which just "seemed like the thing to do at the time." But he neglected sharing his time with his wife and children. His wife divorcing him came as quite a surprise, and this led Palmer "to reassess his life in fundamental ways and to explore the limits of the kind of success he had been pursuing." In this process of reassessment, he reencountered such pleasures as reading and listening to music. The children chose to stay with him, which also forced him to shift his sense of himself and his priorities. A "compulsive problem solver" by his own definition, Brian reexamined "where the thing broke down" and found that he was operating as if a certain value was of the utmost importance to me. Perhaps it was success. Perhaps it was fear of failure, but I was extremely success-oriented, to the point where everything would be sacrificed for the job, the career, the company. I said bullshit. That ain't the way it should be. ${ }^{39}$

With this new outlook about the content of what should be striven for, Brian married a divorcee his age, with four children herself, and discovered by his own account "a new sense of himself" and of "what love can be," "almost a psychologically buoyant feeling of being able to be so much more involved and sharing." ${ }^{40} \mathrm{He}$ also found out that he could "get a lot of personal reward from being involved in the lives of my children." ${ }^{11}$ As Bellah puts it, "the revolution in Brian's thinking came from a reexamination of the true sources of joy and satisfaction in his life." ${ }^{42}$

38 Bellah and others, Habits of the Heart, 3.

39 Bellah and others, Habits of the Heart, 5 .

40 Bellah and others, Habits of the Heart, 5 .

41 Bellah and others, Habits of the Heart, 6 .

42 Bellah and others, Habits of the Heart, 6. 


\section{B. Conversion Regarding Attitude Toward Happiness/ Eudaemonia/Meaning}

The preceding class of moral conversion commonly entails that the agent is, with some degree of awareness, already involved in some kind of meaning-seeking process. The present section considers a class of moral conversion that can take place when a meaning-seeking process is not actively operative: moral conversion as the process through which a person is "awakened" to meaning and becomes involved in a meaning-seeking process. It considers what changes may take place regarding the attitude with which the effort to achieve happiness/ eudaemonia/ meaning is (or is not) undertaken.

A person's attitude in this regard may range from deep involvement (both in the effort to clarify the content of these goals, and to attain them), to utter indifference to the problem, and even to denying that there is a question. As with conversion regarding commitment about right/wrong, there are strong reasons to argue that there is a normative direction for this class of conversion, the ideal being the person who applies his/her conscious faculties explicitly to discerning the content of happiness/eudaemonia/meaning in their own lives. The well-known phrase attributed to Socrates, "the unexamined life is not worth living," declares this well enough, and often philosophers have interpreted their "gadfly" task as that of denouncing when the social environment makes it too difficult to achieve this discernment. Thus Josef Pieper denounced the creation of a "world of labor," an existence devoid of the possibility of philosophical leisure, absolutely oriented toward production; ${ }^{43}$ Simone de Beauvoir identified a variety of human types according to their relation to meaning (the poorest existence being that of the "sub-man," whose life is almost bare facticity, the poverty of his project making his world insignificant and dull), ${ }^{44}$ and Lonergan himself identified the figure of the "drifter," who does nothing very deliberately and who is so lacking in reflective awareness that one may be tempted to ask whether such a life can be called "moral" (or "immoral") at all. ${ }^{45}$

43 Josef Pieper, Leisure, the Basis of Culture, trans. Gerald Malsbary (South Bend, IN: St. Augustine's Press, 1998), 39-48.

44 De Beauvoir, The Ethics of Ambiguity, 42.

45 Bernard Lonergan, Collection (New York: Herder and Herder, 1967), 242. Also 
Instances of people living "unexamined lives" or "drifting" are rather common. But if it is true that human beings are at their core directed toward happiness, eudaemonia, or meaning, and if such a quality has not been permanently expunged or drowned by habit, then the question for "what is the meaning of it all" may yet be reawakened. When this happens - when a person changes his/her attitude so that the content of happiness/ eudaemonia/meaning becomes a pressing question, and its specific achievement is at the center of that person's efforts and energy, we are in the presence of a moral conversion regarding attitude toward happiness / eudaemonia/ meaning. ${ }^{46}$

\section{Narrative Evidence for this Class of Conversion}

Ira Byock, a hospice doctor who specializes in palliative medicine, and is active in the hospice movement, tells the story of Marie Allen, ${ }^{47} \mathrm{a}$ middle-aged woman who was dealt many bad hands, including finding out that her sister Kathy had had an affair with her husband, after which Marie divorced him and broke relations with her sister. Marie then remarried her ex-husband after fifteen years of separation; but her husband died briefly after their second marriage. Shortly after this, Marie learned from her doctor that she had colon cancer in its terminal stages and a very short time to live. While this revelation could have been an occasion for despair, Marie overcame her initial shock quickly and pragmatically; she contacted her sister, and the bad news became an opportunity to heal their relationship. Kathy received Marie in her house and cared for her lovingly during her last year, adapting her life to the needs of Marie's palliative treatment. Marie's relation with Kathy continued to be a little stiff until, finding out from Kathy that her late husband had been actually two-timing both sisters, her

\section{Conn, Christian Conversion, 115.}

46 As to the possibility of shifting away from an attitude of actively seeking meaning/ eudaemonia, this may not, despite philosophers' concerns, be a bad thing in all cases: some people may enjoy routine, at least if it is not of a dehumanizing kind, and some people, who suffer from actually being too reflective, may benefit from it. But insofar as it involves a mindless, unintentional drifting this process is not properly described by the term "conversion," which implies some active endeavor on the part of the moral agent, a higher integration of some sort, and not merely the decreasing directedness of "drifting."

47 Ira Byock, Dying Well: Peace and Possibilities at the End of Life (New York: Riverhead Books, 1997), 35-57. The names have been changed by Byock. 
resentment dissolved in shared laughter. Marie also recomposed her relationship with her estranged daughter Cindy, and her goal became to endure until Cindy's upcoming wedding. Shortly after a year of being diagnosed, Marie died, without pain, and in the care and company of her family.

There seems to be in Marie, before the diagnosis, a general lack of authentic purpose: she lives in resentment, estranged from her loved ones, and seems to fill these gaps in her life by treating herself to material trinkets (she owned a very large collection of shoes, that she gave away without a second thought after the decision was made to live at Kathy's). There does not seem to be an examined choice here. By contrast, once she finds out that she has little time left, she quickly takes the matter into her hands, gives away those things that are not really important to her, and focuses, with a very practical mind-set, on her goal of making of her last moments a time for healing and cultivating her relations with her loved ones. There is a general and rather swift change, first, in her attitude toward happiness in general: rather than lingering in her resentment and adding to it negative feelings provoked by this last revelation, she puts her energy in cultivating positive, loving relations. And secondly, helped by the hospice staff she examines and articulates her concrete goals (e.g., enduring until her daughter's wedding), a move that implies some degree of examination of what she considers meaningful to her life at that stage. In short, Marie converted from an attitude of acid pessimism and lingering resentment to life in general, to an attitude of cherishing life, letting go of grudges and actively seeking "happiness," which for her meant dying in peace after having reconstructed loving relations with the remaining members of her family.

Brian Palmer's story, considered in the previous section, also reveals attitudinal changes. ${ }^{48}$ Palmer's original "utilitarian individualism" seems to have been espoused, to a great degree, unreflectively. There is something paradoxical perhaps (but not uncommon) in the way in which this energetic, goal-driven "problem solver" lived for a long period of time devoid of authentic purpose. The shock and forlornness that followed his divorce provided the setting and the motivation for a conscious examination of his life goals. Not only did he change his goals,

48 Bellah and others, Habits of the Heart, 3-8. 
but he also adopted a different attitude toward happiness/eudaemonia/ meaning, as something deserving explicit examination.

\section{Conversion Regarding Coherence in the Search for Eudaemonia}

It was noted above (in Section 1.C), when describing moral conversion regarding behavioral coherence about right/wrong, that the fact that a person holds certain moral criteria and principles does not guarantee that a person's actions will conform to such principles, particularly when they clash with the immediateness of short-term satisfaction. Similarly, even though a person may clearly appreciate that a certain course of action would be beneficial with respect to his/ her quest for eudaemonia, or more in tune with what is regarded by this person as meaning-giving, the person may still choose to follow a different course of action; or alternatively, perceive him/herself as powerless to choose or engage in the course of action that is understood as the more appropriate to achieve happiness/eudaemonia/meaning.

Classical sources interpret such failures as the result of an internal division in the person's operative principles. Plato described this internal division with the vivid image of a many-headed beast, in which all heads seek at the same time to be fed by a sometimes strong, sometimes weak, human head, representative of reason. ${ }^{49}$ Aristotle gave this phenomenon a detailed treatment in his Nicomachean Ethics, describing "moral weakness" as a disconnection between what the person regards as the rational way to act, and that person's actions. ${ }^{50}$ Sometimes this is the effect of a disconnection between different types of knowledge (i.e., we may know the general rule and not apply it to the concrete situation at hand), and sometimes the effect of the person's knowledge being rendered ineffective by reason of the person being in the grip of his/her emotions - a condition compared to those of being asleep, mad, or drunk.${ }^{51}$ Because of this potential for an internal division/disconnection, sporadic acts of "moral weakness" can be considered a normal part of human life. But it may happen that these inconsistencies become habitual; furthermore, they may become

49 Republic, book IX, 588b-592.

50 Nicomachean Ethics, VII, 1 (1145b).

51 Nicomachean Ethics, VII, 3 (1146b-1147a). 
so resistant to change, so recurrent, that overcoming them in a stable and definitive way comes to be perceived by the person as being beyond their capacities and resources, even if there is clarity in the person's mind regarding the content of happiness/ eudaemonia/meaning. The content is perceived as essentially unattainable, not because of external conditions, but because of one's own weaknesses or insufficiency. The result is loss of hope, despair, defeat.

This is the setting for the third class of moral conversion. Conversion at this point appears as an infusion of new strength, new enthusiasm, new operative hope, on the wings of which the person is able to overcome effectively the obstacles and contrary habits that weighed him/her down, and engage in - and eventually consolidate patterns of behavior that are consistent with what is regarded as the proper direction toward happiness/eudaemonia/meaning.

\section{Narrative Evidence for this Class of Conversion}

Here also many stories may be gathered from the context of addiction and recovery. Leuba's "Subject E," for example, declares:

...all my pangs were due to some terrible remorse I used to feel after a heavy carousal, the remorse taking the shape of regret after my folly in wasting my life in such a way - a man of superior talents and education. I was not much alarmed about the future world. ${ }^{52}$

And John B. Gough, also mentioned by Leuba, says of a person in his situation:

The sense of his degradation and worthlessness does not involve in his mind responsibility for his sin to other; he is absorbed in his own self. He battles against himself, poor slave and outlaw, to conquer, if possible, the place he has lost in society. ${ }^{53}$

The theme of happiness/eudaemonia/meaning appears clearly in these two accounts. More recent narratives of a similar sort can be found in the collection of stories that Alcoholics Anonymous publishes in its

52 Leuba, "A Study in the Psychology of Religious Phenomena," 373-76 (emphasis mine).

53 Leuba, "A Study in the Psychology of Religious Phenomena," 343. 
"Big Book." ${ }^{4}$ One of the earliest narratives of this constantly renewed text is that of "Doctor Bob," one of A.A.'s cofounders. ${ }^{55}$ Doctor Bob got into drinking during his college years; by the time he took up medicine, he was drinking enough to have morning "jitters." His addiction compromised already his ability in class, and in the sophomore year he almost quit school. He had to convince the faculty to let him take his exams (he had turned in examination books empty because he could not hold a pencil), passed them, then remained sober during a couple years of residency during which he was too busy to leave the hospital frequently. Soon after he got his own practice he fell into drinking again; he even developed a phobia to running out of liquor. ${ }^{56} \mathrm{He}$ had to manage his addiction carefully - he needed to be sober enough in the morning to practice medicine, in order to have money for liquor in the evening. He developed tremendous cunning for acquiring and keeping alcohol at home, even during the times of prohibition and living with a vigilant wife.

It is significant that, in Bob's narrative, drinking itself is never specifically censured in terms of right/wrong, whether from a religious or a social point of view. Rather, drinking is mentioned as a continuous obstacle to his fulfilling his aspirations, the cause of many miserable moments, and of living under the constant threat of downfall and shame. This focus places his narrative within the happiness/eudaemonial meaning theme. Indeed, it is a focus on happiness - here emphasizing the aspect of "living a free life" - that reignites in Doctor Bob a strong desire to recover: a moral conversion regarding attitude, but one that does not become immediately effective, and thus requires a conversion regarding coherence as an additional step. Says Doctor Bob:

About the time of the beer experiment [a catastrophic attempt to replace stronger drinks with beer] I was thrown in with a crowd of people who attracted me because of their seeming poise, health and happiness. They spoke with great freedom from embarrassment, which I could never do, and they seemed

54 Alcoholics Anonymous: The Story of How Many Thousands of Men and Women Have Recovered from Alcoholism (Online Edition), 4th ed. (New York: Alcoholics Anonymous World Services, 2001).

55 Alcoholics Anonymous, 171.

56 Alcoholics Anonymous, 176. 
very much at ease on all occasions and appeared very healthy. More than these attributes, they seemed to be happy. I was self conscious and ill at ease most of the time, my health was at the breaking point, and I was thoroughly miserable. I sensed they had something I did not have, from which I might readily profit. I learned that it was something of a spiritual nature, which did not appeal to me very much, but I thought it could do no harm. I gave the matter much time and study for the next two and a half years, but I still got tight [i.e., drunk] every night nevertheless. I read everything I could find, and talked to everyone who I thought knew anything about it. ${ }^{57}$

It was about this time that an unnamed man was recommended to him, and after some long talks managed to get Bob to remain sober for a few weeks. He had a heavy fallback during a conference, but this person again took care of him, and Doctor Bob was able to cease drinking permanently, eventually regaining both his health and selfrespect, and the respect of his colleagues. Bob asks himself the question, what did this man do or say that was different from what others had done or said? In his opinion, a key factor seems to be the fact that this man had been an alcoholic too and had had "most of all the drunkard's experiences known to man, but had been cured by the very means I had been trying to employ, that is to say the spiritual approach. ${ }^{58}$

The current edition of the A.A. book features forty-two selected stories of recovered alcoholics, many similar in essence to the story of Dr. Bob above. The success of the A.A. "12-step method" suggests that the possibility for this type of conversion is not extremely remote or rare: a mere four years after the first Alcoholics Anonymous began meeting, they counted over 100 ex-alcoholics who had recovered using their method; and 100,000 worldwide in 1950 - that is, eleven years afterward. Today A.A. claims over 2 million members worldwide, at different stages of recovery ${ }^{59}$ For the purposes of providing evidence for this class of conversion, this should be sufficient.

57 Alcoholics Anonymous, 178.

58 Alcoholics Anonymous, 180.

59 A.A. Fact File, Prepared by General Service Office of Alcoholics Anonymous (New York: Alcoholics Anonymous World Services Inc., 1998), 16-17. 


\section{Conclusion: A Definition of "Moral Conversion"}

In this paper I have offered a tripartite classification of instances of moral conversion, a classification that applies to moral conversion understood both in terms of right/wrong and in terms of happiness/ eudaemonia/meaning of life. For each class of conversion, a few narratives have been presented, with the double purpose of presenting evidence that such a class of conversion actually takes place, and illustrating with examples what is meant by each class of conversion.

On the basis of the foregoing considerations, a general notion of moral conversion can now be offered. Moral conversion is a process in which a person changes in existential ways related to their understanding of their attitude toward and/or their behavioral habits regarding right/wrong and/or happiness/eudaemonia/meaning of life. The term "existential" is here especially important as denoting the importance of the change, that it is change involving human persons (though by analogy it may also apply to groups), and that it is real, concrete change, involving a great degree of contingency, both because of its concreteness and because of its apparent connection to human freedom.

This categorization, and the tentative definition provided here, are starting points for an in-depth analysis of moral conversion and its implications. How is moral conversion related to a normal process of moral development, to religious conversion, to the goals of psychological therapeutic practice? What philosophical implications follow from characterizing moral conversion as "existential change"? What can be established from the fact of moral conversion with regard to the problem of human freedom? What light does an analysis of the process of moral conversion throw into the discussion regarding the rationality of moral structures and the problem of moral motivation? These are some of these questions that I have addressed in length in my dissertation and that will hopefully become the subject of future articles. 
